\title{
between Medical Science and Cinematography
}

\begin{abstract}
This text examines the history of melancholy starting from Ancient Greece with Hippocrates's Humorism and going up to its current form, namely an isolated subspecies of clinical depression, the term being almost redundant today. Besides, it showcases several examples of melancholic traits in cinema. On another level this work takes a look at how and why the semantics of melancholy veered towards depression in the twentieth century. Feminine melancholy will be a recurring theme throughout this whole text, with a highlight on women's place in every narrative on melancholy that I will analyse.
\end{abstract}

Keywords: history of melancholy, melancholic traits in cinema, depression, feminine melancholy.

\section{Lucia LUPEA}

"luliu Hațieganu" University

of Medicine and Phramacy

lupea.lucia@gmail.com

EKPHRASIS, $1 / 2019$

A Melancholic Exploration of Humanity

(The Solitude of Man)

pp. 93-108

DOI:10.24193/ekphrasis.21.8

Published First Online: 2019/06/27

\section{Introduction}

In this paper, I aim to identify and analyse several important representations of depression in cinematography. In order to create context I decided to present the evolution of melancholy as a concept and define the current pathological form of melancholy, depression. I have chosen three films, different in their medical, artistic and emotional approach of depicting the ever fluctuant and hard to define realm of depression: Red Desert (Michelangelo Antonioni, 1964), Interiors (Woody Allen, 1978), Melancholia (Lars von Trier, 2011) - all of which feature visceral, brutal and accurate images of this pathology and are analyzed in the last chapter of this paper. In the first chapter I try to summarize the history of melancholia as a psychological phenomena - in lack of a better 
term, since it wasn't until the 20th century that it became a pathology. In the second chapter, I focus on the concept of hysteria, the feminine form of melancholia that was predominant during the 19th century while in the third chapter I will define the formal status that depression has today, as a more clearly defined medical condition.

\section{Melancholy-origins}

Melancholy has been associated with brain disorder since the times of Hippocrates when doctors were preoccupied with the humoral nature of the brain and the way in which the four humors can throw the human body out of balance: black bile, yellow bile, saliva and blood - unbalanced quantities of these humors could make the body malfunction, which in turn could favour the apparition of diseases. Built upon the humoral theory, the aristotelian model associated melancholia with exceptional creative traits and geniality, by stating that a certain quantity of black bile is necessary, intrinsic to those showing geniality traits. Aristotle argues that all extraordinary men are melancholic, "why is it that all men who have become outstanding in philosophy, statesmanship, poetry or the arts are melancholic, and some to such an extent that they are infected by the diseases arising from black bile, as the story of Heraclites among the heroes tells?" (Aristotle 155). Among the symptoms that make up the general picture of this pathology are: uncommon behavior, nonconformity, an excessive tendency towards meditation and self-analysis, emotional hypersensitivity and overgrown feelings - turning melancholia into a privileged state of being, a desirable pathology, or an "elite affliction" as Juliana Schiesari calls it (102). This is a positive representation of melancholia, one that excludes women from this patriarchal consensus, "his description of it [melancholia] does suggest a masculine prerogative, the specifically androcentric privilege of all uncommon males [pantes perittoi andres] (Schiesari 104).

What exactly provokes this exclusion of women and the unacknowledgement of melancholia among women? Aristotle talks about two types of melancholy, one natural (that is explained by the overheating of the bile) which "produces cheerfulness accompanied by song, and ecstasy, and the breaking forth of sores, and the like" and the pathological one (which is caused by the excessive cooling of the bile) which "produces apoplexy, torpor, despondency and fear" (Aristotle 161). Melancholia that affected women was often categorized as the second type, as a pathological condition, not a natural state, "if a woman happens to express all the manicdepressive characteristics of uncommon inspiration, it is because she is sick and not because she bears the natural relation to genius that marks the mad poet" (Schiesari 105). The physiological incapacity of women to maintain their body temperature, "the essential coldness of women", seems to unarguably tie together women and the pathological, cold version of melancholia thus marginalizing them, excluding them from the positive representation of melancholy (108). Speaking about Aristotle's male examples, Juliana Schiesari remarks: "if we study, however, the way melancholia has 
been given a particular symbolic status, we discover that melancholia as a discourse exceeds the clinical in a strict sense when it encodes a form of male greatness and eros" (110).

The humoral explanation of melancholia was temporarily abandoned during the inception of Christianity, when melancholia stopped being a disease strictly of the body and switched to being a disease of the soul. The desperate, auto-solitary, hopeless behaviour of a melancholic person was considered a lack of willingness to live and the refuse of divine mercifulness. Mental health issues (the loss of reason) act as a catalyst to the collapse of the human mechanism thus dehumanizing the person affected by melancholy. The loss of reason brings the affected person to an animalic, irrational state. One can observe how this pathology was to blame for two different unfavourable change: on one hand, a moral decay by religious standards and on the other hand, losing the attribute of being human. Moreover, this historical era is responsible for the general stigma associated with depression nowadays. The inability to preserve the soul intact, which is a divine gift, (and for which one needs reason and self-control) resulted in the blaming of the affected person with not trying enough to keep the wholeness bestowed upon him/her by the divine (Solomon 370).

During the Renaissance the association between melancholia and geniality, selfreflective and introspective traits crystallized. Marsilio Ficino picks up the aristotelian model and articulates it with Humorism and with the idea of inspired melancholy, of proximity of the melancholics to the divine, calling it "the divine madness". Soon it became a marker of the aristocrat, of upper class sadness as a social prototype (378). Representations like Hamlet, As You Like It, Every Man in his Humour starts to appear, consolidating this positive aura of melancholy (Lawlor 62). Melancholy was a social construct in these time and not a validated pathology like depression is today.

Although we need to be aware of the distinction between literary representation and social reality, it is appropriate that the role-playing of drama mirrors-and even to some extent constructs-the template for behaviour prompted by a condition that had become fashionable. No doubt all disease is in some way socially constructed but the fashionableness of melancholy in this (and other) periods is particularly illustrative of the way in which narratives of disease are built partly upon cultural representations in literature and the visual arts. (64)

This idealistic philosophical tradition which describes melancholia as a privileged state became truly prolific during the Romantic era. Even today, the term usually voided by medical meaning evokes a romanticized nostalgia, a light meditative sadness usually associated with poetic creativity.

This historical context is important because it shows us that the concept of melancholy has changed profoundly over the centuries. All the different narratives of melancholy gave birth to superlative interpretations and biased cultural repre- 
sentations that failed to accurately represent this psychological condition - sometimes by chance, sometimes on purpose.

\section{Hysteria as a feminine melancholy}

Starting with the seventeenth century doctors started to trace a connection between melancholy and hysteria and a lot of women that were suffering from melancholia were diagnosed with hysteria, melancholy becoming thus superimposable with hysteria, but mostly with women patients. Hysteria as a term originates from Ancient Greece - from the Greek equivalent of the word uterus, which was hystera

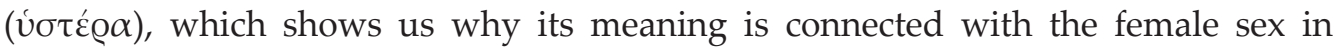
popular understanding. The uterus was seen as a mobile organ, a "wandering uterus", a sort of animal living inside the woman's pelvis which can be re-positioned by using different techniques (sneezing, therapeutically masturbation, scent therapy, etc.). Hysteria's symptoms covered a large palette like uncontrollable emotions, sadness, nervousness, shortness of breath, faintness, lability, sexual desire, insomnia, heaviness in the abdomen or irritability, etc. Doctors associated this large catalog of symptoms with the capriciousness of female nature (Gilman, Sander et al. 286). Hysteria worked as an umbrella-concept and soon started to cover any mental health related issues for women. While some cases of male hysteria were recorded, these were often blamed on a feminine personality of the affected males, an intrusive female component to their male gender (289). Male hysteria did not change the idea that hysteria represents the worst aspects of femininity but reinforced the stereotype of hysteria as a disease of "weak, passive, overly emotional people, whether female or male" (289). Male hysteria was not always described as bearing this trait of femininity, nonetheless it was seen as being different from female hysteria. It lacked the dramatism and spectacle of the female one and it didn't attract as much attention (309). The "uterine theories" persisted in the medical field for quite a long time, the female genital apparatus often being blamed for provoking or being an aggravating factor of hysteria. George Didi-Huberman questioned this hypothesis saying that hysteria is "the neurosis of an immense discursive apparatus, which generated woman as a specific image, compatible with hysteria" (73).

The nineteenth century brought along the sudden development of a wide network of asylums. A well-documented case is the Salpêtrière asylum (France), which I will use as an example of how psychiatric ethics worked at the dawn of psychiatry as a medical science and also illustrate the growing tendency to create a pathology out of everything feminine, using hysteria as a mobile, as described in the previous paragraphs. Salpêtrière was a hospital that gathered Parisian women like prostitutes or simply poor, uneducated women - constituting a vulnerable demographic, which was easy to subdue, or at least easier than a more educated, less socially persecuted group. The last decades of the nineteenth century are especially illustrative for the concept of hysteria and its current worldly meaning, decades in which Salpêtrière, 
then led by Charcot, crossed the limit between clinical and experimental, between illness and provoked symptomatic responses that were made to look like the illness (Gilman, Sander et al. 307). Numerous questions about how these institutionalized women were forced to be ill so that they could be documented and photographed are asked by Georges Didi-Huberman in his work, Invention of Hysteria. These period of time, Salpêtrière was a kind of "feminine inferno" holding four thousand women that were deemed as suffering from a mental health condition.

To understand why Didi-Huberman talks about the invention of hysteria it is important to mention that nineteenth century psychiatry was obsessed with categorizing, labelling, classifying symptoms and putting as many of them together under one unifying concept that explains everything related to those symptoms. In their quest for discovering such a unifying view and supposedly to advance the medical science, doctors were capable of forcing and manipulating the body and psyche of their female patients so that it was in line with whatever concept they were researching, in this case, the concept of Hysteria (286). Photography made possible the realization of hysteria as a valid medical concept, the photo was the necessary medical documentation to use as proof for research (352). All the photos taken at Salpêtrière were documented in an abundant photographic collection called Iconographie photographique de la Salpêtrière (1878). Or as it is underlined in History beyond Freud "disease is real only if it is universal. And it is universal only if it can be seen and the act of seeing reproduced" (379). The medical intention in this hospital was to eliminate the variable of individuality and mask it with a series of common attributes so that it was easier to label.

The fact that the photographic portrait required not only studios and make-up (as if to help the light come into its own) but also headrests, kneebraces, curtains, and scenery is a good indication of the terms of the paradox: an existence was authenticated, but through theatrical means. (DidiHuberman 62)

The relationship between doctors and patients at Salpêtrière is paradoxical in psychiatry. It is a dysfunctional example of what should be mutual relationship based on trust, all under the false pretenses of advancing the medical science of psychiatry. Once admitted, the women became the subject of the camera each and every time their body exhibited any kind of abnormal behaviour like muscle contractions, spasms, convulsions, blackouts, semblances of epilepsy, catalepsy, ecstasies, comas, lethargies, deliria: "a thousand forms within a few moments. The spectacle of the illness" (DidiHuberman 115). A duplicitous relationship developed as women started to perform symptoms of their supposed disease which Charcot could then use as evidence in his investigations. But his view is not unique, it is part of a long-standing European tradition of representing the insane, into which the image of the hysteric must be fitted (Gilman, Sander et al. 359). Thus, they entered this silent treaty giving birth to a "paradox of atrocity" as Didi-Huberman puts it (176). 
In the hell of the Salpêtrière, hysterics incessantly made eyes at their physicians. It was a kind of law of the genre, not only a law of hysterical fantasy (its desire to captivate), but the law of the institution of the asylum itself. And I would say that this institution was structured as a bribe: in fact, every hysteric had to make a regular show of her orthodox hysterical nature to avoid being transferred to the severe division of the quite simple and socalled incurable alienated women. (Didi-Huberman 170)

Moreover, doctors also used techniques such as hypnosis, magnetic plates, sniffing opium, ovarian massage, electrical shocks, playing loud spontaneous noises or blinding the patients with very bright lights to provoke the hysteric attack anytime they wanted. This objectification of patients by themselves and doctors for clinical research resulted in the complete loss of individuality in these women. In the dysfunctional logic behind the medical practice of Salpêtrière, institutionalized woman was constrained to exist "only as the actress of her symptoms" (Didi-Huberman 254).

\section{Depression in modern times}

In the nineteenth century, the development of clinical psychiatry brought about the redefinition of melancholy. Even though it represented a mental disorder it was still associated with non-pathological conditions as mentioned in the first chapter. Depression replaced melancholy, the new term being used to describe a cluster of symptoms associated with melancholy, with a heightened focus on the affective aspects and less on the cognitive ones, which made melancholy easy to associate with conditions like dementia or delirium, "the emergence of the term depression is not just a more or less random change of terminology, but can be understood as a symptomatic part of a process, in which increasing weight is laid on the affective dimension" (Somogy 147). Depression drastically narrows the symptomatic picture when compared to melancholy (which covered a large and vague symptomatic picture) and creates a much clearer, well defined set of tools for diagnosis. During the 20th century, in psychiatric classification both depression and melancholy were mental health conditions, but soon the prominent figures of psychiatry as Kraepelin abandons the diagnosis of melancholy in favour of depression. Hereafter, the replacement of the term melancholia with depression accelerates. Melancholia as a diagnostic term has since disappeared, but with the DSM IV (2000) it reemerges and denotes a subtype of major depressive disorder still valid today but not of great importance in the way we treat depression (Somogy 147).

Two major thought paradigms appeared concerning treatment and diagnosis of depression. The first was Freud's psychoanalysis and the second was Kraeplin's psychobiology. These evolved into today's biopsychosocial model, which tries to place depression at the intersection of several contributing factors such as: genetic, biological, psychological and social. As science is often reductionist, the aetiology of 
depression tends to be broken down into disciplines: psychiatry (biological), clinical psychology (cognitive or interpersonal), and sociology (socio-political). In 1917, Freud published his Mourning and Melancholia which later becomes a central hub in narratives on melancholy, where it is viewed as a reaction to the "the loss of a loved person, or to the loss of some abstraction which has taken the place of one, such as one's country, liberty, and ideal, and so on" (243). The Freudian model is important because it redirects the attention of psychiatrists towards listening to the patients and trying to lift the veil from what conflict could possibly act as a catalyst for depression. Moreover, it also created a focus on the complexity of the human subconscious. However, psychoanalysis is often inefficient as a treatment. Psychoanalysis played a big part in medical practice up until the twentieth century, alongside psychobiology when they were both displaced because of the extreme theories supporting them and medical lack of coherence. In their place, more integrative models for diagnosis and treatment have been developed. A big reproach for psychoanalysis, beginning with the emancipation movements of the early twentieth century, was that it served as a favoring agent, as a suspect cultural institution in the perpetuation of oppression and marginalization of women (Keyes and Goodman 294).

„Psychoanalytic theories of female depression viewed normal femininity as incorporating such qualities as masochism, low self-esteem, dependency, disappointment, and inhibited hostility. These traits inevitably developed once a girl recognized that she lacked a penis (Keyes and Goodman, 295).

Freud describes this realization of not having a penis as a wound to her narcissism for which the daughter blames her mother (195). This kind of theorizing correlates female depression with an inferior anatomy, an incomplete anatomy, the male body serving in this case as the norm. The theories that are based on this kind of arguments contain two errors which result in underestimating feminine depression: "what is advanced as scientific dogma about women merely recycles cultural stereotypes and psychology's claims about female nature grossly underrate the influence of social context" (qtd in Keyes and Goodman 295).

The increased frequency of depression in females compared to males (2:1) (World Health Organisation) was explained through several non-inclusive theories, the most prominent one being the fundamentalist biological explanation. In this paradigm, narratives on female psychology are limited to a reductionary perspective which excludes the socio-political aspect and the women's oppressive social roles, from the aggravating factors for depression and rely on just genes, hormones, the different cerebral anatomy of women, neurochemistry, etc. to explain the disease. Moreover, the twentieth century created a feminine standard, a set of feminine social markers for emotional expressiveness, sensibility and dependency, traits which are also psychiatric symptoms, "femininity was thus rendered pathological" (295). I will come back to this in the last chapter. 
It has been observed that the first depressive episode can be associated with a social external factor (trauma, radical change, abuse, humiliation, etc.). The evolution of the disease that comes next is not as easy to place in a social context and is connected with a set of very intricate neuro-hormonal and psychological problems. Depression has a wholesome clinic picture, with a set of symptoms that are most often disabling for the affected person. The picture includes: depressed mood present most of the day, almost every day, sleep disturbance (insomnia or hypersomnia), loss of interest or anhedonia (we can see this in Justine as she gradually fades out of the reality of her wedding), feelings of worthlessness or guilt, fatigue or loss of energy (in Justine's case, to the point where she is totally immobilized), diminished concentration, ability to think, or make decisions (pseudodementia), weight change due to appetite change, psychosomatic changes, suicidal ideation. In severe cases (or in those associated with mania) symptoms can also include hallucinations, psychosis and delirium (as we can see in Giuliana's character, throughout the whole film). Today, we have two big therapeutical models. The first is conventional therapy, dialogue, and the second is interventional, based on prescribing drugs and electroshock therapy. The physio-pathological mechanism behind depression is unknown, even though there is an abundance of theories in medical science which try to explain depression. The most popular explanation is a balance problem in the chemicals associated with neurotransmitters (low serotonin levels, noradrenalin, dopamine). Because of this, most antidepressants try to boost the levels of these chemicals in the body. The largest category of antidepressants (ISRS-Prozac) block the process of absorption of serotonin back into the blood through cerebral tissue, thus heightening the level of free serotonin in the brain. Even though medication like this helps with the symptoms of depression it doesn't serve as a cure for the disease. Because depression is a recurrent disease, most antidepressants are prescribed for life.

Paradoxically, the most efficient physical treatment for depression is also the most stigmatized: electroshock therapy. This treatment has a success rate of $75 \%-90 \%$ in severe depression cases (Solomon 147). Electroshock therapy is especially effective in cases where effects have to be immediate, like with patients with major suicidal tendencies, given that drugs only start working after several weeks. Electroshock therapy can cause temporary memory loss and some patients exhibit permanent memory loss. For some, memory loss can actually become an aggravating factor in their depression. Another treatment, excessively applied between 1930-1950 (used until 1970) was lobotomy, the disconnection of the prefrontal cortex from the other cerebral lobes. The results of this treatment were disastrous: inertia, lack of emotional response, severe cognitive affection, lack of complexity in conscious thinking. These operations (even though the disabling effects were known) were performed on institutionalized individuals suffering from mental disorders, that lacked any kind of decisional power, left by their families in the hands of doctors. Because of questionable 
psychiatric ethics, it was often that families had to choose between lobotomies and admitting their loved ones to institutions that had inhumane practices.

\section{Representations of depression in cinematography}

As mentioned before, a psychological background for the apparition of affective disorders, such as depression, is created in the 20th century. These psychological theorizations of affective disorders converged to form an image of feminine vulnerability and sensibility, thus rendering the woman as an emotional reservoir. In cinematography, feminine figures are predominant when it comes to depressive/ melancholic characters, reason for which I have chosen three female protagonists: Justine (Melancholia), Eve (Interiors), Giuliana (Red Desert). Von Trier's filmography is infused by this idea of feminine depression, "staging in his heroines acts of protest or refusal" (Honig and Marso 316). This choice of most directors to build female depressive characters is analyzed in Virginia Apperson's book, The Presence of the Feminine in Film “tending to emotions has long been thought of as women's work, contemporary lives are predominantly run by patriarchal values that render sorrow and grief immaterial, and it is, therefore, primarily to the feminine that we continue to turn too for emotional instruction" (260). This creates a cultural phenomena generally, the viewer unconsciously relates depression with the feminine (Honig and Marso 316). Using female characters to portray the state of depression amplifies the depiction of this affliction because of our culture's identification of women as being prone to be more emotional, more sensible and vulnerable. In these three films, we can observe each character's reactions to a debilitating and corrosive malady, the oscillation between feeling and not feeling, the gap between the body and the senses and the overwhelming tension that depression inflicts in these characters. Depression is highlighted in these films by several means: an intricate and realistic imagery, abrasive sound design, set design and lighting, an overall tense atmosphere embedded in the script, the acting and the music.

\section{Melancholia, Lars Von Trier}

Lars von Trier's Melancholia explores the complexity of depression and recomposes this internal state in a packaging that brings together the details of extremely sparking visual content and a dynamic soundscape that sometimes slowly, sometimes throbbingly synchronizes with the evolution of depression in the main character, reaching a climax at the point where Earth and the blue planet collide.

In the first part of the film, entitled Justine, we are witnesses to an overly luxurious and elegant wedding, inopportunely so, creating a strong contrast between the exterior realm, the fastuous celebration of the wedding and Justine's interior state of suffering which is triggered by her mother's toast which is highly critical of marriage and her ex-husband, Justine's father. Her mother's short speech seems to kick-start a melancholic episode in Justine, a retreat towards her inner self, a point 
from which she seems to regress more and more until she reaches a state of mental inconsistency and then a total collapse where she goes into catatonic psychomotor paralysis. Woken up by Claire during the wedding Justine tells Claire "I'm trudging through this grey woolly yarn, and it's clinging to my legs, it's really heavy to drag along". This image also appears in the cinematic sequences from the film's opening moments when Justine very slowly walks through what appears to be a swamp. The ill, dysfunctional body reaches a point where any movement seems like an effort beyond its power, by all means impossible. In one of the most intense scenes yet very revealing for how a severe nervous breakdown can affect the human body, Claire struggles to carry Justine's unresponsive body towards a bathtub. Justine cannot even lift her leg and place it in the water. Later in the evening, she breaks into tears after she tries her favourite dish and discovers that it tastes like ash. What we witness is Justine's depression shutting down her whole sensory apparatus and her total loss of control over her body (in another scene, before reaching Claire's home, Justine can't climb into a taxi). This opens a door to a psychological reality that's violent, paralyzing, nothing like conscious reality. In depression, another significant symptom is ridding the self and the world around it of sense (manifested through an intense feeling of guilt, worthlessness and helplessness). The affected person becomes aware of the existential lack of sense, the vacuum that is the self and from this point they can no longer rebuild a reality that's functional. Justine gives what seems like a calm verdict, almost philosophical, when it comes to the relevance of the world that she lives in: "the earth is evil, we don't need to grieve for it" to which she adds "I know we are alone".

The conclusion seems to be that it doesn't make any sense to live in an imperfect and feeble world like the one Justice lives in, which is where the desire for selfdestruction arises, a desire that becomes visible in the erotic scene where Justine lays naked on the riverbed and seems to pull the blue planet towards her. The collision of the two planets, and with it Justine's end, coincides with the end of a tormented and obsessive psychological state. In depression it is often that the affected person manifests a exacerbated pessimism, like expecting that something devastating, debilitating is going to happen in the near future and there's nothing they can do to stop it. This constant foreshadowing of a catastrophe, which may take the form of a longing or even a wish/dream, is incorporated into Justine's alienated, imperturbable behaviour in the moment when the collision is announced: By analysing Justine in this moment of the film it is easy to draw a parallel to Jacques Hassoun's affirmation "clinical practice teaches us that at the height of distress, melancholics are free of anxiety" (qtd in Elbeshlawly 165). Justine rejects the world so she is an indifferent witness to the disparition of her own self. The film problematizes through this ending the self-destructive tendency that mental health disorder like depression inflicts upon a person. At this point, the viewer starts to empathize with Claire's more familiar anxiety, hence the existence of the two chapters, Justine and Claire. 
Yet, it is Claire's sense of loss at this particular moment that, over and above Justine's melancholic condition, becomes instantly more at home with the restlessness of the human condition as such, with the instability of the subject, with the subject's imaginary unified image falling back into primary fragmentation and, backhandedly, with the instability of von Trier's images themselves and his handheld camera (Elbeshlawly 160). In the last part of the movie, the film enables the viewer to identify with Claire, with her visceral, anxiety fuelled reaction when face to face with the end of the world. Claire is the one that places us in an uncomfortable position where everything seems to have been carved in stone by Justine's melancholic identification with the drive towards death (160). It is what Derrida calls a supplement which produces no relief. The existence of this counterpart to the first chapter (the remainder) constitutes the desire of the viewer to perpetuate herself as a desiring subject even if the final destination is death. The remainder, in other words, is a supplement which supplants melancholia itself (161). In this parallel structure between Claire and Justine, we can observe on the one hand the melancholic tendency to drive towards death and on the other the acute desire to go on, to resist an apocalyptic plot, in the only way we can imagine the end of the world, in a mode and as a vestige of survival beyond the annihilation that will therefore not have been total. Even though Lars von Trier seems to discourage this tendency by neutralizing the world wholly.

It is precisely this remainder which urges us to repeat the experience of watching the film and perhaps in particular the end scene from the safety of our surrounding reality. What we really enjoy is not the orgasmic collision and the end of the world, but the notion that this can always be played again, because it is this repetitive gesture that corresponds with the idea of our survival as desiring subjects even while/after watching the world coming to a catastrophic end. (Elbeshlawly, 161)

Lars von Trier's Melancholia counts on the reproduction of depression as a visual spectacle that goes by at varying speeds. The film opens with several sequences where the characters seem almost static but then there are moments where time seems to be heavily compressed (like when Justine disappears) only to switch back to slow moving moments which seem to indicate towards an internal state which doesn't follow a linear logic. Judith Pinter comments this irregular development of the film by saying "Melancholia is the phenomenon of melancholy itself" as its "slow pace, its recurring leitmotif-like sentences and images in place of a narrative, offer the viewer a condition rather than a story" (61).

\section{Interiors, Woody Allen}

The maniacal component of depression is well represented in Interiors in Eve's character, forming a well-rounded picture of manic-depressive bipolar disorder. During the film, Eve oscillates between the two constitutive states, from suicidal 
tendencies and emotional low points to energy excesses which pushes her to organize the space around her in an aesthetically pleasing way again and again maniacally, in a never ending effort. Eve is visibly affected by small imperfections in how objects are placed in the space around her, in the colour palette of rooms, in the chaotic world that she inhabits. A relevant example of this is the scene in the film's beginning where she asks Joey to buy a very expensive vase to bring the interior design of their home into balance.

In the first lines, Arthur describes the way that this psychological rupture has occurred in the family. "The truth is she'd created a world around us that we existed in ... where everything had its place, where there always was a kind of harmony". A world where everything has an order and everything has its place, "the harmony of Eve's projected cosmos is colourless and aesthetically oppressive" (Bailey 75). "She was very beautiful" Arthur explains, "Very pale and cool in her black dress with never anything more than a single strand of pearls. And distant. Always poised and distant". Arthur describes the ordered and hyper-aesthetic world that Eve projects around them like this: "it was like an ice palace". In this setting, where the pathology is clear (or at least the path towards the pathology is clear), Arthur notices Eve's mental collapse: "then suddenly one day, out of nowhere, an enormous abyss opened up beneath our feet" - this is the moment where she totally breaks away from the reality of her life and the life of her family, retreating to an inner dimension, a psychological dimension that comes with its own exigencies. The disparity between the outer world and Eve's relentless efforts to organize, cosmetize this world so that it coincides with her imagination, turns Eve into a captive, a prisoner of her own projections. At the same time this disparity is emotionally debilitating as it makes her unable to relate to her husband, to her daughter, to her family. Eve's efforts to bring the two worlds together is very obvious throughout the movie. Towards the end of the film Joey, Eve's daughter, tells her mother: "I think you're uh, really too perfect to live in this world,", "I mean all the beautifully furnished rooms, carefully designed interiors, everything so controlled. There wasn't any room for any real feelings. None between any of us." Eve's answer to her incompatibility with the world, which she seems to be too good for in the eyes of her daughter, is to immerse herself in interior decoration and create a new world around her, a broken world that no member of her family can really be a part of.

because its effort to subject and subjugate reality to consciousness, to shape a disordered world according to the dictates of the human imagination, ultimately imprisons the self in its own projections, rendering the world outside it so alien and insufferably chaotic that the self's only recourse is to keep closing windows until everything is interior and there's no outside there anymore. (Bailey 80) 
The dissociative episode Eve goes through affects everyone around her, creating an emotional void in every character, especially affecting the two big daughters. Joey can't seem to find her place, she feels incomplete, purposeless, "I feel the real need to express something, but I don't know what it is I want to express or how to express it" and Renata talks about a redundancy she feels about her poetry and her life. At the same time, their supportive yet seemingly blind reaction to the psychological crisis their mother is going through is to push her, with the attitude of a therapist, towards what paradoxically suits her the best, which is: "a manic devotion to transforming human habitats into artworks through interior decoration" - unknowingly, they are pushing their mother back to the origins of her illness, the maniacal component, the excessive interior order that serves as compensation for the never ending chaos that is the outside world (Bailey 76). We also get a hint that Eve could overcome her depression, especially after the break-up with Arthur, her husband. She even tells Joey about the progress she feels she has made in fighting her condition and that she even hopes she might get back together with Arthur - who subtracted himself from the evermore complex web of emotions. Renata also supports her mother's illusions, creating a rather confusing state around Eve, which only serves as a catalyst for the development of her mother's condition.

Eve's suicide, when she walks into a tormented sea, fully determined and calm, can be interpreted as a liberation of her family from the tight fabric in which she unconsciously wrapped everyone, which she carefully weaved in her efforts to create a perfect world, but unfortunately an emotionally neutralizing one. In the end Joey and Renata show affection towards one another, dissolving the envy Joey had always felt for her sister. The other daughter, Flyn, outgrows her artificial nature and appears with a transfigurated aspect at her mother's funeral.

\section{Red Dessert, Antonioni}

Red Dessert places us in the maculate italian landscape of industrial Ravenna (in the midst of the socio-economic transformations of the 50's and 60's). In a world of factories, alienating and disruptive noises that suggest both the sound of aggressive and intrusive technology and the tense, neurotic psychological state of Giuliana, the main character that, throughout the movie, tries to break free of the isolation that her psychological breakdown made her a prisoner of but seems unable to find comfort in anything. Giuliana is Ugo's wife, who is a manager at one of the factories that make up the industrial architecture of Ravenna. The film debuts with Giuliana and her son, Valerio, walking through an oppressive landscape that reminds us of a desert, which inflicts a state of confusion in Giuliana, face to face with a mechanized world. Giuliana's depression appears on this backdrop of a new world emerging that she doesn't belong in. She tells Conrad, the only person she seems to be synchronized to, as he is also affected by the process of industrialization: "I'm afraid I won't make it", 
"What are you afraid of?" Conrad asks, "I'm afraid of streets, factories, colors, people - everything".

The film enables us to closely watch Giualiana's efforts to connect with the morphed new world. Giualiana's psychological state seem to be in a continuous dialogue with the industrial, mechanized world. All her breakdowns, from the psychotic episodes to the hallucinations and the attempted suicide during the car crash are simply her body's response to the impossibility to connect to the new world. When Ugo talks about the car crash, he doesn't even think about it as being an attempt at suicide. Ugo blames the accident on her anxiousness and doesn't seem to understand her psychological reactions. Without trying to incriminate the modern world, Antonioni merely points at how the modern world can act as a catalyst to a dissociative state, "progress rudely intrudes on human intimacy" (Antonioni 285). Antonioni presents the ambivalent nature of the feelings his character has when she has to confront the transformations of modern Italy.

The lines and curves of factories and their chimneys can be more beautiful than the outline of trees, which we are already too accustomed to seeing. It is a rich world, alive and serviceable. I have to say that the neurosis I sought to describe in Red Desert is above all a matter of adjusting. (Antonioni 288)

The film's color palette is closely tied to how Giuliana perceives the world. There is only one scene when Antonioni chooses to use colors in their natural hue, unaltered the scene where Giuliana makes up a story for her sick son. The story is about a little girl that lives on a beach, far away from the city and the fast paced life associated with it - "A little cove among the rocks" says Giuliana, "She had never realized they were like flesh. And the voice ... at that moment the voice was so sweet'. 'Who was singing?' asks her child. 'Everything was singing. Everything". The same musical theme supports the opening scene of the film that shows the foggy, grayscale of the industrial landscape, suggesting that there is beauty in both environments. The juxtaposition of these very contrasting types of scenography highlights the fractured existence of Giuliana and the isolated imagined world of the beach/island is in fact the idealized reality Giuliana craves. The factories are colored very vividly, which results in an impressive visual effect, even though demanding. Antonioni uses color not only to highlight the industrial landscape but to allow us to see through Giuliana's eyes as her wole sensory apparatus seems to be exaggerated and her perception altered.

Yet 'natural' variations in colour are not enough: in order to emphasize the intensity of the aesthetic experience in Red Desert, Antonioni directly altered colours to achieve his desired effect by painting trees, buildings and other features in the film. The deliberate artificiality of colour in Red Desert mimics the technological artifice of the industrial landscape and also emphasizes the complexities of colour perception. (Gandy 227) 
Antonioni also explores the psychosis that is related to spatiality, the fobia generated by the modern ultra-mechanized environment that swallows the individual (Conrad and Giuliana, walking through the huge station, composed of several red metallic constructions). In many scenes Antonioni uses fog or smoke to even out the space and to make it indistinct, this way erasing any human trace and creating confusion, spatial disorientation, which is an important component of how Giuliana's condition manifests (Gandy 224). In one of the scenes, Giuliana faces the others in a dense fog, which for a few moments covers them, leaving her alone and alienated, the same way most interactions seem to make her feel.

\section{Works Cited}

Antonioni, Michelangelo. The Architecture of Vision: Writings and Interviews on Cinema. University of Chicago Press, 2007.

Apperson Virginia and Beebe John. The Presence of the Feminine in Film, Cambridge Scholars Publishing, 2009.

Aristotel, Problems II. William Heinemann LTD London, Harvard University Press, 1957.

Bailey, Peter J. The Reluctant Film Art of Woody Allen. The University Press of Kentucky, 2001.

Didi-Huberman, Georges. Invention of Hysteria: Charcot and the Photographic Iconography of the Salpêtrière. MIT Press, 2004.

Elbeshlawly, Ahmed. Woman in Lars von Trier's Cinema, 1996-2014. Palgrave Macmillan, 2016.

Freud, Sigmund. Three Contributions to the Theory of Sex. CreateSpace Independent Publishing Platform, 2018.

Freud, Sigmund. "Mourning and melancholia". The Standard Edition of the Complete Psychological Works of Sigmund Freud, Volume XIV (1914-1916): On the History of the PsychoAnalytic Movement, Papers on Metapsychology and Other Works, 1957, pp. 237-258.

Gandy, Matthew. "Landscapes of Deliquescence in Michelangelo Antonioni's Red Desert". Transactions of the Institute of British Geographers, Wiley, 2003, pp. 218-237.

Gilman, Sander L. et al. Hysteria Beyond Freud. University of California Press, 1993.

Honig, Bonnie and Lori J Marso. Politics, Theory, and Film: Critical Encounters with Lars von Trier. Oxford University Press, 2016.

Keyes, Corey L.M. and Sherryl H.Goodman. Women and Depression : A Handbook for the Social, Behavioral and Biomedical Sciences. Cambridge University Press, 2006.

Kramer, Peter D. Listening to Prozac: A Psychiatrist Explores Antidepressant Drugs and the Remaking of the Self. Viking Press, 1993.

Lawlor, Clark. From Melancholia to Prozac : A History of Depression. Oxford University Press, 2012.

Munteanu, Andrada. The aesthetics of depression in the work of Lars von Trier. Universitetet I Bergen, 2016.

Pintér, Judit. 'The Lonely Planet: Lars von Trier's Melancholia'. Translated by J. Tucker. Senses of Cinema. No. 61, December 2011. sensesofcinema.com/2011/feature-articles/thelonely-planet-lars-von-triers-melancholia. Accessed 18 Aug. 2018. 
Schiesari, Juliana. The Gendering of Melancholia: Feminism, Psychoanalysis, and the Symbolics of Loss in Renaissance Literature. Cornell University Press, 1994.

Solomon, Andrew. Demonul Amiezii: O anatomie a depresiei. 2nd ed., Humanitas, 2017.

Varga, Somology. "From Melancholia to Depression: Ideas on a Possible Continuity". Philosophy, Psychiatry, \& Psychology, Johns Hopkins University Press, 2013, pp.141-155. World Health Organisation, Gender Disparities in Mental Health, Department of Mental Health and Ssubstance Dependence 